\title{
9. Chromosome Studies in Five Sexually Abnormal Patients
}

\author{
By Sajiro Makino, ${ }^{*)}$ Akira Tonomura, ${ }^{*)}$ Masahiro Mizutani, ${ }^{*)}$ \\ Hiroo SAKaKuRA, ${ }^{* *)}$ Shuntaro KUMAKIRI, ${ }^{* *)}$ Senzo ITOGA, ${ }^{* * *}$ \\ and Masao YAMAFUJI****)
}

(Comm. by Yoshimaro TANAKA, M.J.A., Jan. 12, 1962)

Remarkable technical development of late years in mammalian tissue culture and cytology has surprisingly facilitated detailed studies of chromosomes in mammals including man. The application of improved cytogenetic techniques to human subjects has proved a sudden development of observations on human syndromes. During the years 1959-1960, many significant associations have been discovered between abnormal chromosome patterns and human disease states.

In the senior author's laboratory (S.M.), studies on associations between chromosomal variation and clinical disorders have been in progress. The present paper deals with the chromosome abnormalities observed in five cases of congenital and endocrine syndromes.

Table I. Some clinical and laboratory data in five patients under study

\begin{tabular}{|c|c|c|c|c|c|c|}
\hline $\begin{array}{l}\text { Patient } \\
\text { no. }\end{array}$ & Age & $\begin{array}{l}\text { Legal } \\
\text { sex }\end{array}$ & Clinical diagnosis & $\begin{array}{c}\text { Sex } \\
\text { chromatin }\end{array}$ & $\begin{array}{c}\text { 17-keto- } \\
\text { steroids } \\
\text { (per day) }\end{array}$ & $\begin{array}{l}\text { Gonado- } \\
\text { trophin } \\
\text { (per day) }\end{array}$ \\
\hline 1 & 44 & $\sigma^{\pi}$ & Klinefelter's syndrome & positive & $11.23 \mathrm{mg}$ & $48 m u$ units \\
\hline 3 & 18 & 오 & Turner's syndrome & negative & $1.09 \mathrm{mg}$ & $20 m u$ units \\
\hline 6 & 21 & 우 & Testicular feminization & negative & $22.0 \mathrm{mg}$ & $24 m u$ units \\
\hline 11 & 22 & 우 & Adrenogenital syndrome & positive & $20.15 \mathrm{mg}$ & $\begin{array}{lr}\text { G.*. } & 220.0 \mathrm{r} \\
\text { G.A. } & 75.0 \mathrm{r}\end{array}$ \\
\hline 12 & 24 & 우 & Defect of vagina & positive & & $\begin{array}{ll}\text { G.*. } & 225.0 \mathrm{r} \\
\text { G.B. } & 120.0 \mathrm{r}\end{array}$ \\
\hline
\end{tabular}

*) 17-ketosteroids and gonadotrophin were measured when the patient was

12 years of age. **) Estrogen: $17.7 \gamma$, and pregnanediol: $1.24 \mathrm{mg}$. ***)

Gonadotrophin was measured according to Crooke's method.

Clinical diagnosis of the patients and sampling of the material for study were made in the Medical School, Keio University, Tokyo. The clinical data are as shown in Table I. Bone-marrow biopsies sampled from patients by means of sternal puncture provided the material for this study.

A part of the samples from each case was exposed to 0.00002 per cent colchicine solution immediately after sampling and kept for 1 to 2 hours at $37^{\circ} \mathrm{C}$. The remaining part was cultivated for 24 hours at $37^{\circ} \mathrm{C}$ and exposed to colchicine for 1 to 2 hours at $37^{\circ} \mathrm{C}$. For short term culture of specimens, a synthetic medium of the formula of McCoy et al. (1956) after slight modifications was used, 10 per cent inactivated bovine serum

*) Zoological Institute, Hokkaido Univ., Sapporo. **) Department of Obsterics and Gynecology, Medical School, Keio Univ., Tokyo. ***) Department of Pediatrics, Medical School, Keio Univ. ****) Department of Urology, Medical School, Keio Univ. 
being added. Then, the samples thus provided were concentrated by centrifugation at $1,000 \mathrm{rpm}$ for 3 to 5 minutes. Droplets of the cell suspension thus obtained were placed on slides and mixed with an approximately equal volume of water. After being left for ten to fifteen minutes, the samples were stained with acetic dahlia for fifteen to twenty minutes, covered and squashed. The chromosomes were analysed and arranged according to the Denver conventions into seven autosomal groups in a descending order of size from 1 to 22 , and a sex-chromosome group which was excluded from general numbering. The results of chromosome counts are given in Table II with some other related data.

Table II. Chromosome constitutions of five patients based on marrow specimens

\begin{tabular}{|c|c|c|c|c|c|c|c|c|}
\hline $\begin{array}{l}\text { Patient } \\
\text { no. }\end{array}$ & 42 & $\begin{array}{l}\text { Chromosom } \\
43 \quad 44 \quad 45\end{array}$ & e nur & $47 \quad 48$ & $\begin{array}{l}\text { No. of } \\
\text { cells obs. }\end{array}$ & $\begin{array}{l}\text { Modal number } \\
\text { of chroms. }\end{array}$ & $\begin{array}{c}\text { Sex } \\
\text { chrom. }\end{array}$ & $\begin{array}{l}\text { Legal } \\
\text { sex }\end{array}$ \\
\hline 1 & & & 1 & 16 & 17 & 47 & $\mathrm{XXY}$ & $\sigma^{7}$ \\
\hline 3 & & 13 & 1 & & 14 & 45 & XO & 우 \\
\hline 6 & & 1 & 7 & & 8 & 46 & $X Y$ & 우 \\
\hline 11 & 1 & 2 & 36 & 2 & 41 & 46 & $\mathrm{XX}$ & 우 \\
\hline 12 & & 2 & 12 & & 14 & 46 & $\mathrm{XX}$ & 오 \\
\hline
\end{tabular}

1. Chromosomes of a patient with Klinefelter's syndrome. This patient (no.1) was phenotypically male, aged 44 years, whose defect was clinically diagnosed as Klinefelter's syndrome. The clinical and laboratory data of the case are presented in Table I. Testicular biopsy indicated small atrophic hyalinized tubules with atrophic spermatogenesis. The sex-chromatin test was positive.

Chromosome counts were made on the basis of 17 reliable metaphasic cells (Table II): 16 cells showed 47 chromosomes while the remaining one had 46 chromosomes. The ideogram analysis made in two cells having 47 chromosomes revealed the occurrence of 5 small acrocentric elements in the complement which is suggestive of the existence of a $\mathrm{Y}$ chromosome, while 16 medium-sized submedian chromosomes indicate the presence of two X's among them (Figs. 1-2). The above findings adequately justify the conclusion that the cells with 47 chromosomes contain two X chromosomes and one Y chromosome, in addition to 44 autosomes. It is then evident that this sex chromatin-positive male patient has an XXY sex-chromosome complement typical of Klinefelter's syndrome.

2) Chromosomes of a patient with Turner's syndrome. This patient (no. 3) is a 19 year old Japanese girl whose clinical diagnosis proved to be Turner's syndrome (Table I). Her face bears typical features as a patient with Turner's syndrome, epicanthus being obviously detectable. Albeolo process of upper jaw protrudes sharply and hard palate is "ogival" palate-like. The development of the mandible is incomplete. This patient shows an assortment of a few congenital abnormalities which characteristically consist of slightly developed webbing of the neck, broad shield-like chest, shortness of stature, thickset body that is called "stocky build", and cubitus valgus at 
25 degree in the region of the elbow joint. Her feet show also an abnormality that seems to be pes cavus. Surgical examinations indicated that the patient has normal but atrophic female genitalia. She is characterized by a small uterus, long and narrow in outline, being $4 \mathrm{~cm}$ in length and $0.6 \mathrm{~cm}$ in width. Both ovaries measured $3 \mathrm{~cm}$ in length and $0.3 \mathrm{~cm}$ in width, having remained in an rudimentary

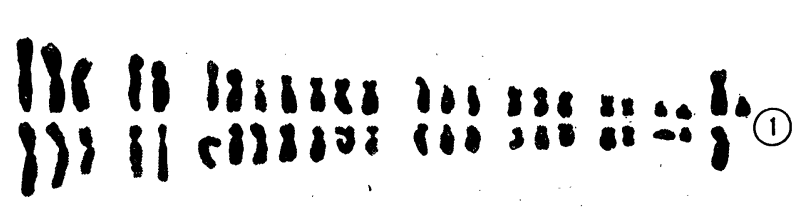

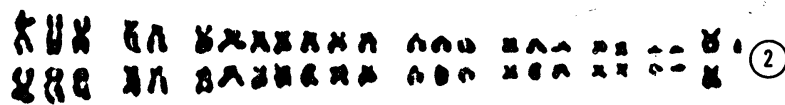

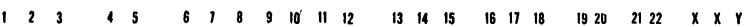

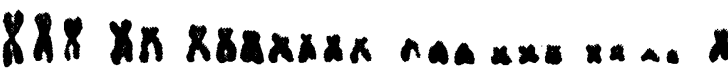

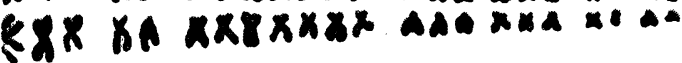

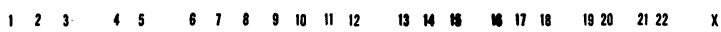

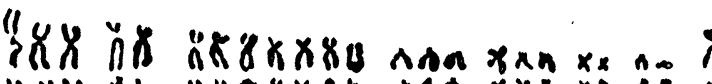

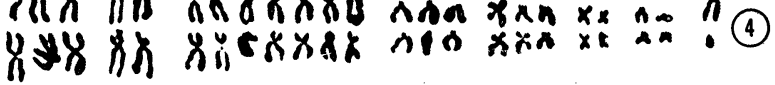

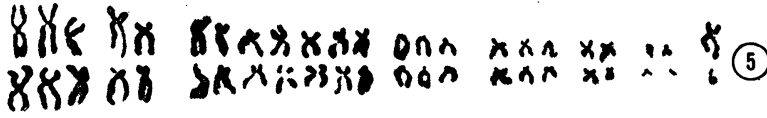

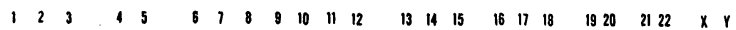

Figs. 1-5. Analyses of the chromosomes in bone-marrow cells. 1-2; Klinefelter's syndrome, 47 chromosomes. 3; Turner's syndrome, 45 chromosomes. 4-5; testicular feminization, 46 chromosomes. state. Oviducts of both sides, however, are of a normal female, being $10 \mathrm{~cm}$ in length. Histological examinations revealed that the ovary is composed of stroma cells without germcells. This patient has chromatin-negative nuclear sex.

Exact chromosome counts made with 14 reliable metaphasic cells resulted in the findings that 13 cells had 45 chromosomes, only one showing 46 chromosomes (Table II). Morphological analysis of chromosomes was made in two cells having 45 chromosomes (Fig. 3). It was shown that each cells contained 4' small acrocentric chromosomes proving the absence of the $\mathrm{Y}$, while there occurred 15 medium-sized submedian chromosomes with a sign of the presence of the $X$. The results obtained justify the conclusion that the present case submitted to chromosome analysis has the chromosome constitution of 44 autosomes and one $\mathrm{X}$ chromosome, being an $\mathrm{XO}$ sex chromosome complex characteristic of Turner's syndrome so far reported.

3) Chromosomes of a patient with testicular feminization. This patient (no. 6) is a 21 year old Japanese whose legal sex was female. Clinical and laboratory data are as shown in Table I. A small biopsy of a gonadal specimen of the patient offered a structure of testicular 
tissue, being in immature state with no spermatogenesis. In spite of the occurrence of cryptorchid testes and primary amenorrhea, the external genitalia are of female type, together with a well-developed breast and a femine habit. On the basis of the results of clinical and histopathological examinations her defect was diagnosed as testicular feminization.

The number of chromosomes was studied in 8 cells which permitted reliable counts. Seven cells showed consistent counts of 46 with the remaining one showing 45 chromosomes (Table II). Ideogram analysis made in two cells having 46 chromosomes revealed that they had a normal male complement, because there occurred 15 medium-sized submedian chromosomes, one of which may be an X element and 5 smallest acrocentric chromosomes, one of them being the Y (Figs. 4-5). The findings justify the conclusion that this chromatin-negative patient has a male chromosomal constitution with an XY chromosome complement.

4) Chromosomes of a patient with adrenogenital syndrome. The specimens for study were derived from a 24 year old Japanese woman (no. 11) whose defect was clinically diagnosed as adrenogenital syn-

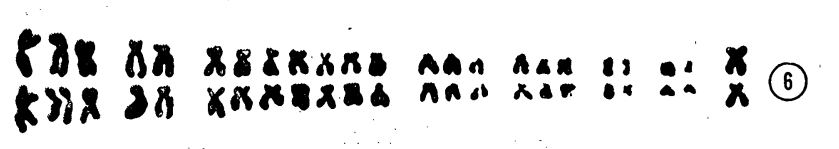

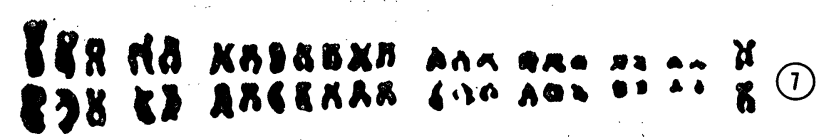

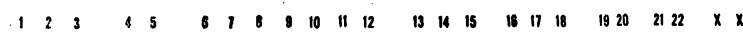

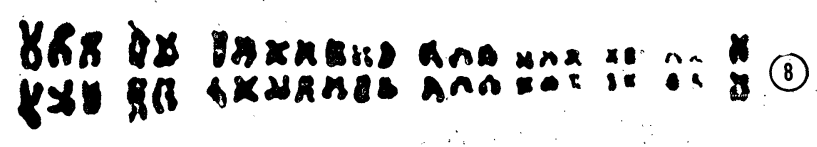

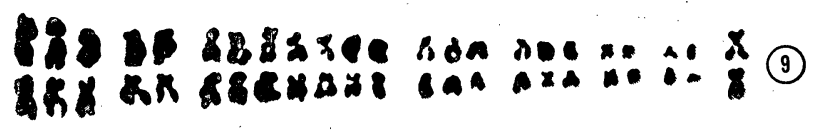

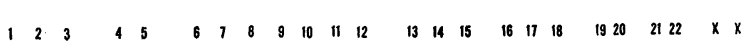

Figs. 6-9. Analyses of the chromosomes in bone-marrow cells. 6-7; adrenogenital syndrome, 46 chromosomes. $8-9$; defect of vagina, 46 chromosomes. containing 46 chromosomes in each (Table II). Two 46-chromosome cells were morphologically analysed. It was shown that each represented a normal female complement because of the occurrence of 16 medium-sized submedian chromosomes including two $\mathrm{X}$ elements and 4 small acrocentric elements without the $\mathrm{Y}$ (Figs. 6-7). It is then reasonable to conclude that this patient is genotypically female, 
on account of her normal female chromosomal constitution with an $\mathrm{XX}$ sex-mechanism.

5) Chromosomes of a patient with defect of vagina. The patient (no. 12) under study was a 24 year old Japanese woman whose abnormality diagnosed clinically as defect of vagina; the clinical and laboratory data are summarized in Table I. Her uterus was bicornic, and very small in size, while her oviducts and ovaries were normal in size, as well as in histological structure.

Chromosome counts were made in 14 reliable metaphasic cells. As seen in Table II, 12 cells contained 46 chromosomes with the other two showing 45 chromosomes. On the basis of the analysis of chromosomes in two 46-cells, it was found that the present chromatinpositive case consistently showed a chromosome constitution of normal female, consisting of 44 autosomal elements and an XX sex chromosome complement (Figs. 8-9).

Remarks. During the years 1959-1960, various types of sexual aberrations in man have been found associated with abnormalities of the sex-chromosomes. Advances in this field of studies are being made so rapidly that it is difficult to offer a review in any final form, though recent contributions are admirably summarized by Ford, ${ }^{2)}$ Miles, ${ }^{4)}$ Ferguson-Smith, ${ }^{12}$ Miller, ${ }^{5)}$ Sohval, ${ }^{6)}$ Harnden and Jacobs ${ }^{37}$ and some others. Since the first report of mongolism and of Klinefelter's and Turner's syndromes, more than 30 distinct varieties of cytogenetic abnormalities have been recorded. In addition, many extensive chromosomal observations have been carried out on cases of pseudo- and hermaphroditism as well as in various other diseases and malformations.

Since the first report by Jacobs and Strong (1959), the great majority of phenotypic males classified under the general term Klinefelter's syndrome have been found to possess two X chromosomes and one $\mathrm{Y}$; from that time on numerous confirmatory reports have appeared. Recently it has been reported that not all of these chromatin-positive males do in fact represent an XXY condition. Information so far obtained has indicated that there occur, in the chromatin-positive Klinefelter's syndrome, XX/XXY (46/47) mosaic cases, an $\mathrm{XXY} / \mathrm{XX} / \mathrm{XY} / \mathrm{XO}(47 / 46 / 45)$ mosaic, and an $\mathrm{XXY}$ condition with trisomy for chromosome 15. In the chromatin-negative Klinefelter's syndrome, an XY (46) constitution and an XY/XXY (46/47) mosaic case were reported. Further, the chromosome constitutions were studied in cases which show signs of Klinefelter's syndrome and mongolism or some other mental defects: for example, chromatinpositive Klinefelter's syndrome showing an XXXY (48) condition in mentally defective males, an XXX/XX mosaic or an XXY plus a small unpaired element, probably a deleted $\mathrm{X}$, in mentally retarded 
males, and an XXY plus trisomy for chromosome 21 in mongoloids.

The majority of chromatin-negative Turner's syndrome cases, a condition shown by a failure of development of secondary sexual characters, have been reported to possess 45 chromosomes with XO sex-chromosome constitution. Recent investigations have presented several other cases of patients with Turner's syndrome showing different chromatin patterns and different chromosomal constitutions. For instance, there are chromatin-positive cases with an XO-mechanism (45) or an XX constitution (46), a male Turner's syndrome having an XY condition (46), two cases of XX/XO (46/45) mosaicism, a chromatinnegative case with an $\mathrm{XX} / \mathrm{XO}$ mosaicism together with trisomy or monosomy for one of smaller autosomes, one case of an XO condition involving trisomy for one of the largest chromosomes (46), two variants of Turner's syndrome showing XO/XY mosaicism, and so on.

A type of phenotypic females with the male chromosomal constitution is a clear-cut clinical syndrome usually referred to as testicular feminization. A case of this syndrome studied in the present investigation was found to possess a karyotype characteristic of normal male, its XY sex-chromosome constitution indicating evidence of a sex chromatin-negative condition. The present findings supplement those of other authors. It has been stated that testicular feminization is associated with either a sex-linked recessive gene or a sexlimited autosomal dominant gene.

A case of adrenogenital syndrome dealt with in this paper showed clinically adrenal virilism and an increase of 17-ketosteroid. Cytologically this case was found to be a female by the fact that it has a positive sex-chromatin pattern and 46 chromosomes with an XX sex-determining mechanism. A patient who was diagnosed as defect of vagina also was proved as a female on the cytological basis in the present study. Very probably the abnormal sexual differentiation as seen in these patients may be due to some environmental factor which caused endocrine unbalance and affected the course of development at a critical stage after the sex had been normally determined.

There is no doubt but that chromosome investigation in human subjects will play in the future a significant part in establishing a differential diagnosis of patients with abnormal sexual development. Cytogenetic studies of these subjects are not only of scientific importance, but also of significance to clinicians in the medical field.

\section{References}

1) Ferguson-Smith, M. A. (1961): Prog. Med. Genetics,, chap. 8, 292-334.

2) Ford, C. E. (1960): Am.J. Human Genet., 12, 104-117.

3) Harndern, D. G., and Jacobs, P. A. (1961): Brit. Med. Bull. 17, 206-212.

4) Miles, C. P. (1961): Stanford Med. Bull., 19, 1-18.

5) Miller, C. J. (1961): Recent Advances in Human Genetics, chap. 3, 39-55.

6) Sohval, A. R. (1961): Am. J. Med., 31, 397-441. 